\title{
Efficacy of Aflibercept for DME with Different OCT Types
}

\author{
Yuan Tao \\ Department of Ophthalmology, Jinan Second People's Hospital, Shandong \\ Mingrong Kou \\ Department of Ophthalmology, Qilu Hospital of Shandong University, Shandong \\ Xia Yang \\ Department of Ophthalmology, Pingyuan County First People's Hospital, Shandong \\ Yixiao Li \\ Jining Medical University, Shandong \\ Shuting Li \\ Department of Ophthalmology, Qilu Hospital of Shandong University, Shandong \\ Hui Zhao \\ Department of Ophthalmology, Qilu Hospital of Shandong University, Shandong \\ Hong Wang ( $\nabla$ dr.wanghong@163.com ) \\ Department of Ophthalmology, Qilu Hospital of Shandong University, Shandong \\ Weiguo Li \\ Neurosurgery Department, Qilu Hospital, Shandong University, Shandong
}

\section{Research Article}

Keywords: aflibercept, diabetic macular edema, OCT

Posted Date: June 22nd, 2021

DOI: https://doi.org/10.21203/rs.3.rs-612172/v1

License: (c) (i) This work is licensed under a Creative Commons Attribution 4.0 International License. Read Full License 


\section{Abstract}

Background: This study aimed to assess efficacy differences of aflibercept by intravitreal injection for diabetic macular edema (DME) with different OCT types.

Methods: according to OCT morphology, 128 patients (128 eyes) with DME were divided into the diffuse retinal thickening (DRT; 41 patients, 41 eyes), cystoid macular edema (CME; 47 patients, 47 eyes), and serous retinal detachment (SRD; 40 patients, 40eyes) groups. All patients were treated by intravitreal injection of $0.5 \mathrm{mg}(0.05 \mathrm{~mL})$ aflibercept according to the 3+prn regimen. BCVA (LogMAR) and central foveal thickness (CFT) among the three groups at baseline, and 1 month, 3 months, 6 months and 12 months after treatment, respectively, were assessed.

Results: At 1 month, 3 months, 6 months and 12 months after treatment, improvements in BCVA and CFT in the three groups showed statistical significance $(P<0.05)$. BCVA improvement was better at all time points in the DRT group compared with the SRD group $(P<0.05)$. BCVA improvement was also better in the CME group compared with the SRD group at 6 months and 12 months post-treatment $(P<0.05)$. At 1 month, 3 months and 6 months after treatment, CFT differences among the three groups had no statistical significance $(P>0.05)$, while at 12 months post-treatment, CFT values among the three groups had significant differences $(F=3.77, P=0.0269)$. at 12 months after treatment, CFT improvement was better in the DRT and CME groups compared with the SRD group $(\mathrm{P}<0.05)$.

Conclusion: aflibercept by intravitreal injection could significantly improve visual acuity in DME patients with different OCT types and reduce CFT. At the initial treatment of 12 months, CFT and BCVA improvements in the DRT and CME types were the most pronounced.

\section{Background}

Diabetes is one of the most serious health problems facing the world in the 21 st century, and its incidence is positively related to economic status. In 2015 , there were about 415 million adults with diabetes, a number expected to reach 642 million by 2040 [1]. Diabetic macular edema (DME) is the main reason for visual loss in patients with non-proliferative diabetic retinopathy. DME refers to retina thickening and the deposition of hard exudate by the accumulation of extracellular fluid within the diameter of both optic discs in the macular center due to diabetes. DME can be diagnosed by fundus photography and direct ophthalmoscope. Besides, it can be classified into the diffuse retinal thickening (DRT), cystoid macular edema (CME), and serous retinal detachment (SRD) categories by optical coherence tomography (OCT) [2]. Anti-vegf therapy is a first-line treatment option for macular edema involving the fovea. Aflibercept is a recombinant VEGF and placental growth factor inhibitor, with a significant therapeutic effect on DME [3]. The purpose of this retrospective study was to analyze the therapeutic effects of aflibercept in DME patients with different OCT types, to better determine patient prognosis in DME with different types and to guide the formulation of therapeutic regimens for DME.

\section{Methods}

\section{General Data}

This was a retrospective study, including 128 eyes treated with aflibercept by intravitreal injection from August 2018 to March 2019 in our hospital (the $3+$ prn regimen was adopted, i.e., treatment performed according to visual acuity and OCT examination results of patients after 3 consecutive intravitreal injections of aflibercept once per month at the beginning) (see Table 1 for the general data of patients). According to OCT results, all the eyes were divided into three groups (41 with DRT, 47 with CME and 40 with SRD). inclusion criteria were: (1) diagnosis of diabetes, >18 years of age, and stable general condition; (2) OCT suggesting macular edema. One eye was randomly selected for observation in patients with binocular disease. Exclusion criteria were: (1) poor imaging quality due to opacity of refractive media, e.g., in case of vitreous hemorrhage or cataract; (2) anti-VEGF therapy or retinal laser photocoagulation therapy performed; (3) fundus diseases, including retinal vein occlusion and wet age-related macular degeneration; (3) follow up not possible. The general data of all patients are shown in Table 1.

Table 1

General patient data

\begin{tabular}{|c|c|c|c|c|c|c|c|}
\hline Group & Age (year) & $\begin{array}{l}\text { Duration of diabetes } \\
\text { (year) }\end{array}$ & NPDR & PDR & $\begin{array}{l}\text { Duration of DME } \\
\text { (year) }\end{array}$ & BCVA & $\mathrm{CFT}(\mu \mathrm{m})$ \\
\hline DRT group (41 cases) & $62.13 \pm 12.19$ & $11.04 \pm 5.73$ & $18(41.46 \%)$ & $23(58.54 \%)$ & $1.09 \pm 0.58$ & $0.74 \pm 0.23$ & $469.28 \pm 76.07$ \\
\hline $\begin{array}{l}\text { CME group (47 } \\
\text { cases) }\end{array}$ & $63.41 \pm 13.02$ & $12.97 \pm 5.89$ & $22(46.80 \%)$ & $25(53.19 \%)$ & $1.26 \pm 0.51$ & $0.69 \pm 0.24$ & $496.13 \pm 73.76$ \\
\hline $\begin{array}{l}\text { SRD group ( } 40 \\
\text { cases) }\end{array}$ & $62.87 \pm 11.88$ & $10.66 \pm 6.25$ & $16(40.00 \%)$ & $24(60.00 \%)$ & $1.29 \pm 0.53$ & $0.71 \pm 0.22$ & $499.25 \pm 78.62$ \\
\hline$F, t, X^{2}$ & 0.12 & 1.92 & 0.4076 & & 1.65 & 0.52 & 1.95 \\
\hline$P$ & 0.8899 & 0.1506 & 0.8156 & & 0.1960 & 0.5975 & 0.1472 \\
\hline
\end{tabular}

\section{Methods}


According to OCT data in medical records, macular edema could be classified into the following categories. (1) DRT has the highest incidence among all DME types, and is characterized by macular spongiform retinal swelling on OCT images. (2) OCT images in CME are characterized by cystoid spaces in the cavity, reduced reflectivity, and increased reflection between the cystoid cavities in the macular area. (3) OCT images in SRD are characterized by a shallow swelling of the retina and low reflection under RPE [2]. A total of 128 eyes with DME were included. According to OCT results, they were divided into three groups: DRT, 41 eyes; CME, 47 eyes; SRD, 40 eyes. Best corrected visual acuity (BCVA) data were converted to LogMAR for statistical analysis. Central retinal thickness (CFT) was measured by the same experienced technician. The measurement was repeated three times and the average value was further assessed. BCVA, CFT and other clinical data in the three groups were recorded before injection and at 1 month, 3 months, 6 months and 12 months of follow-up, respectively. All patients were observed by the same senior ophthalmologist. OCT images were obtained on a Zeiss CIRRUS HD-OCT. BCVA was obtained by the same experienced senior optometrist. This retrospective study was approved by the Ethics Committee of Qilu Hospital, Shandong University (2019-091).

\section{Intravitreal Injection}

Levofloxacin eye drops (Santen Pharmaceutical Co., Ltd.) was administered 3d before injection at 4 times a day, with the conjunctival sac cleaned to prevent infection. The patient was placed in the supine position, and oxybuprocaine hydrochloride eye drops (Santen Pharmaceutical Co., Ltd.) was administered for surface anesthesia. Surgical drapes were routinely sterilized. A total of $0.05 \mathrm{~mL}$ of aflibercept ( $0.5 \mathrm{mg}$ of aflibercept) was extracted with a $1 \mathrm{ml}$ injector. The needle was injected vertically through the pars plana at a distance of 3.5-4.0 mm from the cornea limbus at the inferotemporal region of the operative eye. Then, the drug was injected into the vitreous cavity. After injection was completed and no detection of intraocular hemorrhage or other complications, the antibiotic coulentum was applied to cover the eye. All patients and their family members signed informed consent for the operation. The surgeries were performed by the same skilled physician. In case the following conditions were found during re-examination after injection, intravitreal injection surgery was repeated: $₫ 5$ letters decreased in BCVA; $\nabla$ OCT showing an increase in CRT (>100 $\mu \mathrm{m})$; $\varangle$ FFA examination showing an increase in fluorescein leakage. With a BCVA $>84$ letters $(20 / 20)$ at two consecutive re-examinations, or three consecutive re-examinations of visual acuity not further improved after at least two consecutive intravitreal injections of anti-VEGF drugs, intravitreal injection was terminated.

\section{Statistical Treatment}

The SPSS21.0 software was used for statistical analysis. Measurement data were compared by ANOVA, and enumeration data by the chi-square test. BCVA and CFT among groups were compared by ANOVA, and BCVA and CFT before and after treatment within the groups by paired t-test. P<0.05 was considered statistically significant.

\section{Results}

\section{Changes in BCVA (LogMAR) among the three groups before and after treatment}

At baseline, there was no significant difference in BCVA (LogMAR) among the three groups $(F=0.52, P=0.5975)$. At 1 month, 3 months, 6 months and 12 months after treatment, respectively, BCVA improvement in the three groups showed statistical significance, with improvement in the DRT group being the most significant. BCVA was better in the DRT and CME groups compared with the SRD group at 1 month after treatment, with statistical significance ( $t=$ 5.2034, $\mathrm{P}<0.01 ; \mathrm{t}=2.8670, \mathrm{P}<0.05)$; BCVA difference between the DRT and CME groups was not statistically significant. BCVA was better in the DRT and CME groups compared with the SRD group at 3 months after treatment, with statistical significance $(t=4.9955, P<0.01 ; t=2.9030, P<0.05)$; $B C V A$ difference between the DRT and CME groups was not statistically significant. the DRT and CME groups had no statistically significant difference in BCVA at 6 months after treatment. Meanwhile, visual acuity improvement was better in the DRT group compared with the SRD group ( $t=4.9349$, $P<0.01$ ), and the CME and SRD groups had no statistically significant difference. BCVA difference between the DRT and CME groups was not statistically significant at 12 months after treatment, while visual acuity improvement was better in the DRT group compared with the SRD group $(t=5.8450, P<0.01)$. Visual acuity improvement was also better in the CME group compared with the SRD group $(\mathrm{t}=3.8138, \mathrm{P}<0.01)$ (Table 2, Fig. 1).

Table 2

Changes in BCVA (LogMAR) among the three groups at baseline and 1 month, 3 months, 6 months and 12 months after treatment

\begin{tabular}{|c|c|c|c|c|c|c|c|c|c|c|c|c|c|}
\hline Group & $\begin{array}{l}\text { BCVA } \\
\text { before } \\
\text { treatment }\end{array}$ & $\begin{array}{l}\text { BCVA at } \\
1 \text { month } \\
\text { after } \\
\text { treatment }\end{array}$ & $t$ & $P$ & $\begin{array}{l}\text { BCVA at } \\
3 \text { months } \\
\text { after } \\
\text { treatment }\end{array}$ & $t$ & $P$ & $\begin{array}{l}\text { BCVA at } \\
6 \text { months } \\
\text { after } \\
\text { treatment }\end{array}$ & $t$ & $P$ & $\begin{array}{l}\text { BCVA at } \\
12 \\
\text { months } \\
\text { after } \\
\text { treatment }\end{array}$ & $t$ & $P$ \\
\hline $\begin{array}{l}\text { DRT } \\
\text { group } \\
\text { (41 } \\
\text { cases) }\end{array}$ & $\begin{array}{l}0.74 \pm \\
0.23\end{array}$ & $\begin{array}{l}0.37 \pm \\
0.17\end{array}$ & 8.2836 & 0.0000 & $\begin{array}{l}0.39 \pm \\
0.19\end{array}$ & 7.5122 & 0.0000 & $\begin{array}{l}0.39 \pm \\
0.18\end{array}$ & 7.6734 & 0.0000 & $\begin{array}{l}0.40 \pm \\
0.20\end{array}$ & 7.1427 & 0.0000 \\
\hline $\begin{array}{l}\text { CME } \\
\text { group } \\
\text { (47 } \\
\text { cases) }\end{array}$ & $\begin{array}{l}0.69 \pm \\
0.24\end{array}$ & $\begin{array}{l}0.44 \pm \\
0.18\end{array}$ & 5.7130 & 0.0000 & $\begin{array}{l}0.46 \pm \\
0.21\end{array}$ & 4.9444 & 0.0000 & $\begin{array}{l}0.46 \pm \\
0.19\end{array}$ & 5.1512 & 0.0000 & $\begin{array}{l}0.47 \pm \\
0.21\end{array}$ & 4.7295 & 0.0001 \\
\hline $\begin{array}{l}\text { SRD } \\
\text { group } \\
\text { (40 } \\
\text { cases) }\end{array}$ & $\begin{array}{l}0.71 \pm \\
0.22\end{array}$ & $\begin{array}{l}0.52 \pm \\
0.20\end{array}$ & 4.0416 & 0.0001 & $\begin{array}{l}0.55 \pm \\
0.21\end{array}$ & 3.3272 & 0.0013 & $\begin{array}{l}0.54 \pm \\
0.21\end{array}$ & 3.5352 & 0.0007 & $\begin{array}{l}0.59 \pm \\
0.21\end{array}$ & 2.4954 & 0.0147 \\
\hline$F$ & 0.52 & 6.78 & & & 6.27 & & & 6.09 & & & 8.74 & & \\
\hline$P$ & 0.5975 & 0.0016 & & & 0.0025 & & & 0.0030 & & & 0.0003 & & \\
\hline
\end{tabular}




\section{Changes in CFT among the three groups before and after treatment}

At baseline, there was no statistically significant difference in CFT among the DRT, CME and SRD groups $(F=1.95, P=0.1472)$. CFT improvement among the three groups at 1 month, 3 months, 6 months and 12 months after treatment showed statistical significance, with improvement in the DRT group being the most significant. CFT differences among the three groups at 1 month and 3 months after treatment were not statistically significant, while statistically significant differences were found at 6 months and 12 months $(F=4.37, P=0.0147 ; F=5.65, P=0.0045)$. At 6 months after treatment, $C F T$ improvement was better in the DRT and CME groups compared with the SRD group ( $t=4.0843, P<0.05 ; t=2.8889, P<0.05)$. CFT difference between the DRT and CME groups was not statistically significant. At 12 months after treatment, CFT improvement was better in the DRT and CME groups compared with the SRD group ( $t=$ 4.5154, $\mathrm{P}<0.01 ; \mathrm{t}=3.6306, \mathrm{P}<0.05)$. Meanwhile, CFT difference between the DRT and CME groups was not statistically significant (Table 3 and Fig. 2 )

Table 3

Changes in CFT at baseline and 1 month, 3 months, 6 months, and 12 months after treatment

\begin{tabular}{|c|c|c|c|c|c|c|c|c|c|c|c|c|c|}
\hline Group & $\begin{array}{l}\text { CFT } \\
\text { before } \\
\text { treatment }\end{array}$ & $\begin{array}{l}\text { CFT at } 1 \\
\text { month } \\
\text { after } \\
\text { treatment }\end{array}$ & $t$ & $P$ & $\begin{array}{l}\text { CFT at } 3 \\
\text { months } \\
\text { after } \\
\text { treatment }\end{array}$ & $t$ & $P$ & $\begin{array}{l}\text { CFT at } 6 \\
\text { months } \\
\text { after } \\
\text { treatment }\end{array}$ & $t$ & $P$ & $\begin{array}{l}\text { CFT at } \\
12 \\
\text { months } \\
\text { after } \\
\text { treatment }\end{array}$ & $t$ & $P$ \\
\hline $\begin{array}{l}\text { DRT } \\
\text { group } \\
\text { (41 } \\
\text { cases) }\end{array}$ & $\begin{array}{l}469.28 \pm \\
76.07\end{array}$ & $\begin{array}{l}279.19 \pm \\
41.66\end{array}$ & 14.0339 & 0.0000 & $\begin{array}{l}282.82 \pm \\
42.05\end{array}$ & 13.7361 & 0.0000 & $\begin{array}{l}287.34 \pm \\
43.42\end{array}$ & 13.3005 & 0.0000 & $\begin{array}{l}291.62 \pm \\
42.97\end{array}$ & 13.0206 & 0.0 \\
\hline $\begin{array}{l}\text { CME } \\
\text { group } \\
\text { (47 } \\
\text { cases) }\end{array}$ & $\begin{array}{l}496.13 \pm \\
73.76\end{array}$ & $\begin{array}{l}288.64 \pm \\
44.62\end{array}$ & 16.5009 & 0.0000 & $\begin{array}{l}295.21 \pm \\
45.61\end{array}$ & 15.8833 & 0.0000 & $\begin{array}{l}297.39 \pm \\
46.10\end{array}$ & 15.6642 & 0.0000 & $\begin{array}{l}299.30 \pm \\
45.09\end{array}$ & 15.6090 & 0.0 \\
\hline $\begin{array}{l}\text { SRD } \\
\text { group } \\
\text { (40 } \\
\text { cases) }\end{array}$ & $\begin{array}{l}499.25 \pm \\
78.62\end{array}$ & $\begin{array}{l}301.03 \pm \\
55.39\end{array}$ & 13.0355 & 0.0000 & $\begin{array}{l}306.93 \pm \\
55.20\end{array}$ & 12.6619 & 0.0000 & $\begin{array}{l}319.21 \pm \\
58.84\end{array}$ & 11.5954 & 0.0000 & $\begin{array}{l}326.26 \pm \\
57.85\end{array}$ & 11.2087 & 0.0 \\
\hline$F$ & 1.95 & 2.16 & & & 2.58 & & & 4.37 & & & 5.65 & & \\
\hline$P$ & 0.1472 & 0.1193 & & & 0.0798 & & & 0.0147 & & & 0.0045 & & \\
\hline
\end{tabular}

\section{Complications during the treatment}

No adverse reactions occurred in all patients during the treatment.

\section{Discussion}

In the current retrospective study, the anti-VEGF drug aflibercept administered by intravitreal injection was effective in the treatment of DME. BCVA and CFT changes in different DME types classified by OCT under the same therapeutic regimen were analyzed. The results showed that visual acuity in the DRT and CME groups was most improved with aflibercept administered by intravitreal injection for DME (the $3+$ prn regimen was adopted).

With economic development, the number of individuals with diabetes is increasing around the world. DME is the main reason for visual loss in patients with non-proliferative diabetic retinopathy. The underlying mechanism is that hypoxia, oxidative stress and inflammation triggered by increased blood glucose upregulate various cytokines such as vascular endothelial growth factor, angiogenin, tumor necrosis factor, interleukins and matrix metalloproteinases. Then, the blood-retinal barrier (BRB) is destroyed, leading to the macular edema [4]. The therapeutic methods for macular edema include traditional laser photocoagulation therapy, anti-VEGF therapy, hormone therapy and micropulse laser therapy [5]. Among these, anti-vegf therapy has become the first-line treatment.

The differences in therapeutic effects among the three different DME types were discussed in this retrospective study. Studies indicated that DRT might be the early stage of DME, as a type of DME without cystoid change or subretinal fluid accumulation under OCT. VEGF plays a prominent role in the physiopathological mechanism of its pathogenesis; therefore, anti-VEGF therapy has a significant effect on eyes diseased with the drT type [6]. CME is caused by cystoid change due to liquefactive necrosis of Müller cells on the basis of DRT. In addition to VEGF, its pathogenesis is also related to prostaglandins and inflammatory cytokines [7]. The pathogenesis of the SRD type remains unclear. It may be related to continuous inflammation, ischemia and hypoxia, which lead to deformed structure of the retinal pigment epithelium and dysfunctional retinal pigment barrier, causing the leakage of retinal and choroidal blood vessels and depositing proteins under the retina [8].

\section{Conclusion}

This study showed that intravitreal injection of aflibercept exerts therapeutic effects on DME. Among DME patients with the three different disease types, the DRT and CME groups showed the best therapeutic effect. This was a retrospective study, and the etiologic mechanisms of different DME types remain unknown and deserve further investigation. In addition, the mechanisms underlying the observed therapeutic effect differences in terms of molecular biology 
and pathophysiology have not been explored. In addition, due to the single center design and the limited number of patients in this study, the possible slight differences in efficacy between the DRT and CME groups may be overlooked. Therefore, further studies with larger sample sizes are warranted.

\section{List Of Abbreviations}

BCVA, best corrected visual acuity

BRB, blood-retinal barrier

$\mathrm{CFT}$, central retinal thickness

CME, cystoid macular edema

DME, diabetic macular edema

DRT, diffuse retinal thickening

OCT, optical coherence tomography

SRD, serous retinal detachment

\section{Declarations}

\section{Ethics approval and consent to participate}

This retrospective study was approved by the Ethics Committee of Qilu Hospital, Shandong University (2019-091). All procedures performed in studies involving human participants were in accordance with the ethical standards of the institutional and/or national research committee and with the 1964 Helsinki declaration and its later amendments or comparable ethical standards. Informed consent was waived by the committee because of the retrospective nature of the study.

\section{Consent for publication}

Not applicable.

\section{Availability of data and materials}

The data set supporting the results of this article are included within the article.

\section{Competing interests}

The authors declare that they have no conflict of interest.

\section{Funding}

This study was supported by Project of Jinan Science and Technology Bureau.

\section{Authors' contributions}

YT and MRK conceived and coordinated the study, designed, performed and analyzed the experiments, wrote the paper and revised the paper. $X Y$ and $Y X L$ carried out the data collection, STL and HZ carried out data analysis. All authors reviewed the results and approved the final version of the manuscript.

\section{Acknowledgements}

Not applicable.

\section{References}

1. Ogurtsova K, da Rocha Fernandes JD, Huang Y, Linnenkamp U, Guariguata L, Cho NH, Cavan D, Shaw JE, Makaroff LE: IDF Diabetes Atlas: Global estimates for the prevalence of diabetes for 2015 and 2040. Diabetes Res Clin Pract 2017, 128:40-50.

2. Sander B, Best J, Johansen S, Kessel L, Moldow B: Fluorescein transport through the blood-aqueous and blood-retinal barriers in diabetic macular edema. Curr Eye Res 2003, 27(4):247-252.

3. Korobelnik JF, Do DV, Schmidt-Erfurth U, Boyer DS, Holz FG, Heier JS, Midena E, Kaiser PK, Terasaki H, Marcus DM et al: Intravitreal aflibercept for diabetic macular edema. Ophthalmology 2014, 121(11):2247-2254.

4. Wisniewska-Kruk J, Hoeben KA, Vogels IM, Gaillard PJ, Van Noorden CJ, Schlingemann RO, Klaassen I: A novel co-culture model of the blood-retinal barrier based on primary retinal endothelial cells, pericytes and astrocytes. Exp Eye Res 2012, 96(1):181-190.

5. Chen G, Tzekov R, Li W, Jiang F, Mao S, Tong Y: SUBTHRESHOLD MICROPULSE DIODE LASER VERSUS CONVENTIONAL LASER PHOTOCOAGULATION FOR DIABETIC MACULAR EDEMA: A Meta-Analysis of Randomized Controlled Trials. Retina 2016, 36(11):2059-2065. 
6. Sheu SJ, Lee YY, Horng YH, Lin HS, Lai WY, Tsen CL: Characteristics of diabetic macular edema on optical coherence tomography may change over time or after treatment. Clin Ophthalmol 2018, 12:1887-1893.

7. Chan GCY, Kamble R, Muller H, Shah SAA, Tang TB, Meriaudeau F: Fusing Results of Several Deep Learning Architectures for Automatic Classification of Normal and Diabetic Macular Edema in Optical Coherence Tomography. Annu Int Conf IEEE Eng Med Biol Soc 2018, 2018:670-673.

8. Wang YZ, Zheng Z: Application research progress of optical coherence tomography combined with microperimetry in diabetic macular edema. Chinese Journal of Ocular Fundus Disease 2018, 34:404-407.

\section{Figures}

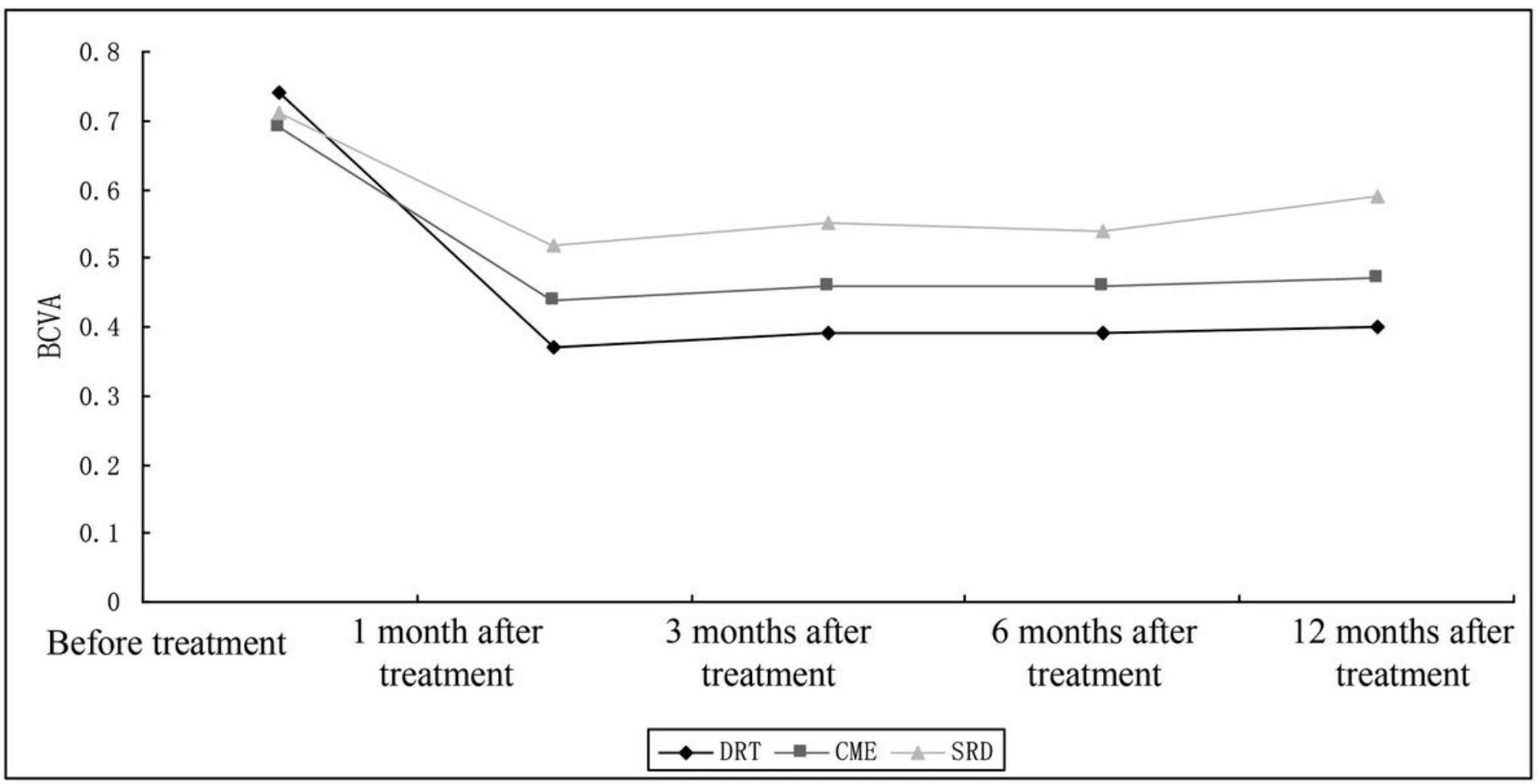

\section{Time}

Figure 1

Changes in BCVA (LogMAR) among the three groups at baseline and 1 month, 3 months, 6 months and 12 months after treatment 


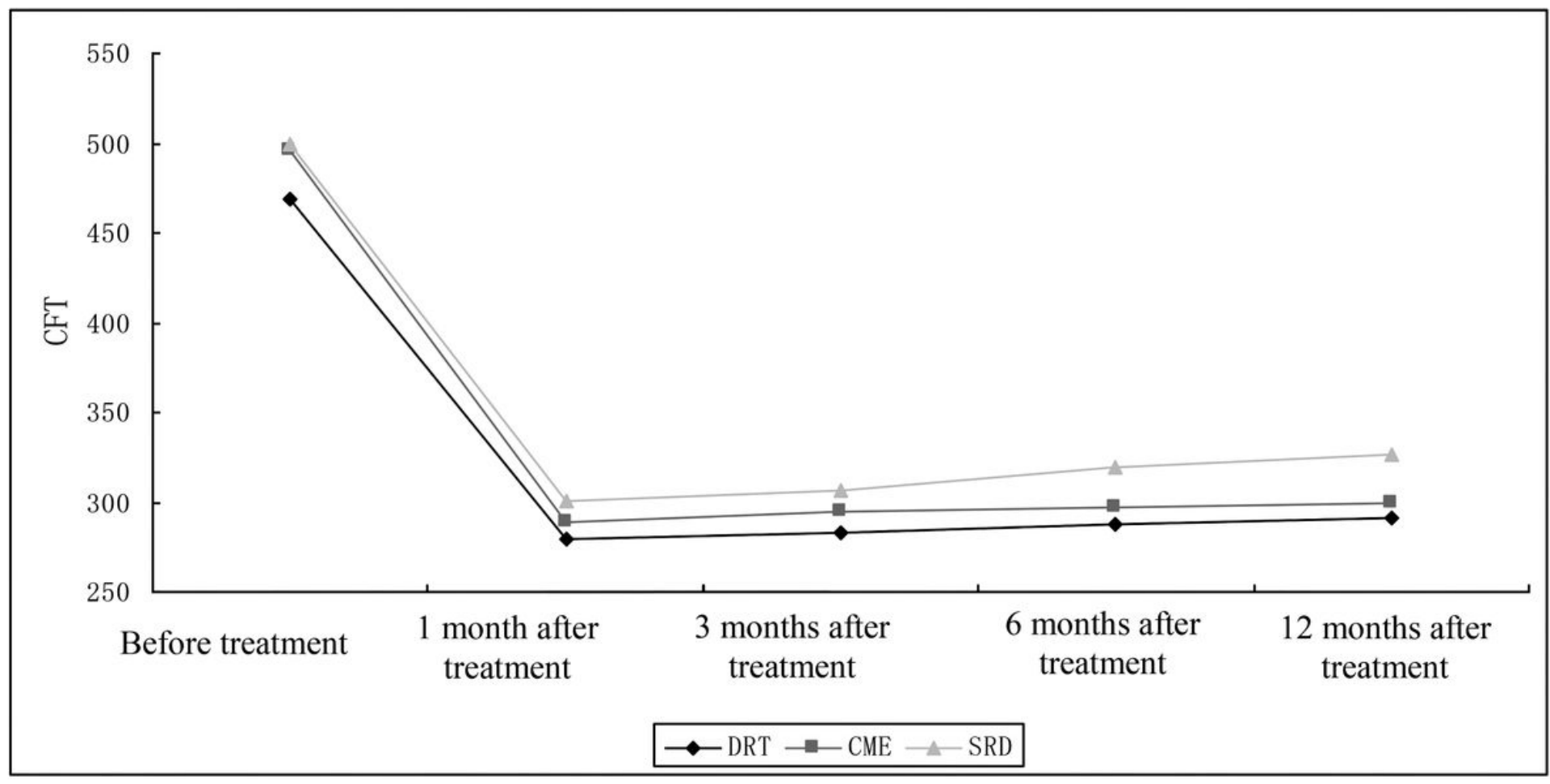

Time

Figure 2

Changes in CFT at baseline and 1 month, 3 months, 6 months and 12 months after treatment 